\title{
Egressos de Odontologia: o sonho da profissão liberal confrontado com a realidade da saúde bucal
}

\author{
Isabel Alves Gomes Pinheiro*; Luiz Roberto Augusto Noro**
}

* Especialista em Dentística pela UFRN

** Professor do Programa de Pós-Graduação em Saúde Coletiva e do Departamento de Odontologia da UFRN

\section{RESUMO}

Modificações no campo do trabalho em Odontologia demostram uma transformação no mercado, na prática e na formação do cirurgião-dentista. Procura-se um novo profissional para atender as necessidades de saúde da sociedade, com foco na atenção em saúde bucal coerente com a realidade epidemiológica. O objetivo deste estudo foi avaliar a inserção dos egressos de Odontologia da Universidade Federal do Rio Grande do Norte no mercado de trabalho e sua relação com o currículo e atividades de educação permanente. A pesquisa foi desenvolvida por meio de questionário autoadministrado, composto por variáveis relativas ao tempo de ingresso no mercado de trabalho, participação em pós-graduação, ações desenvolvidas ao longo da graduação, inserção profissional e satisfação profissional. Os resultados demostraram que o serviço privado é, ainda, um grande empregador, fato que caracteriza o perfil do profissional e corrobora a grande predominância de disciplinas clínicas no currículo. A participação do aluno em atividades complementares configura-se estratégia essencial para a perspectiva da futura inserção profissional, assim como flexibilização curricular. Apesar da transição sinalizada pelas perspectivas de universalização do acesso público à saúde bucal, são necessários esforços ímpares na educação permanente para que a Odontologia alcance seu espaço valorizado perante a sociedade e cumpra efetivamente seu papel de profissão de saúde.

Descritores: Papel Profissional. Desenvolvimento de Pessoal. Odontologia. Mercado de Trabalho. Recursos Humanos em Odontologia.

\section{INTRODUÇÃO}

O campo de trabalho para os profissionais da saúde, de maneira geral, existe em função dos padrões epidemiológicos, culturais e econômicos da população, do modelo de prestação de serviços e do crescimento da oferta de mão de obra.

Durante algum tempo a característica predominante da profissão odontológica foi o trabalho individual, voltado para a técnica, centrado na doença e com ênfase no curativo, por meio de uma prática eminentemente liberal e elitista. Baseando-se nesse conceito de mercado, o cirurgião-dentista passou por um período (1960 a 1980) de "prosperidade financeira”, o que caracterizou o paradigma da época ${ }^{1}$.

Este quadro propiciou à Odontologia brasileira as seguintes características, elencadas durante a VII Conferência Nacional de Saúde: ineficácia, ineficiência, descoor- 
denação, má distribuição, baixa cobertura, alta complexidade, enfoque curativo, caráter mercantilista e monopolista, assim como inadequação da formação de recursos humanos ${ }^{2}$.

Refém das heranças comerciais e privadas desta fase da Odontologia brasileira, a organização dos serviços públicos de saúde bucal tem forte influência deste modelo, o que leva aos movimentos ligados à Reforma Sanitária propor novas perspectivas para a área de saúde bucal ${ }^{3}$. Busca-se transformar o acesso a saúde bucal como um direito do ser humano, para além da possibilidade dos que podem pagar por melhores sorrisos, melhores linguagens, melhores relações amorosas ${ }^{4}$.

Esta dimensão é sinalizada a partir do surgimento do Sistema Único de Saúde (SUS) o qual prevê a universalização do acesso à saúde, o atendimento integral do indivíduo, a participação popular e a descentralização das ações colocando a Odontologia na perspectiva de uma profissão de saúde, o que contribui para o surgimento de postos de trabalho na área pública, à medida que há a consolidação deste sistema ${ }^{5}$.

Essas modificações demostram uma transformação não só do mercado, mas também na prática e na formação do dentista. Traça-se um novo perfil do profissional na sociedade voltado não apenas para assistência odontológica e sim para a atenção em saúde bucal, ocupando-se da promoção de saúde, prevenção das doenças, diagnóstico precoce e assistência odontológica, coerentes com a realidade social e epidemiológica.

As diretrizes curriculares nacionais trazem mudanças inovadoras nos cursos de graduação em Odontologia dirigindo a formação de um profissional sintonizado com as demandas sociais, em consonância com a consolidação do SUS, para que haja maior politização das ações de saúde bucal ${ }^{6}$.

O objetivo deste estudo foi avaliar a inserção dos egressos de Odontologia da Universidade Federal do Rio Grande do Norte (UFRN) no mercado de trabalho, visando obter indicadores de adequação do currículo do curso de graduação, assim como propor ações da instituição na perspectiva da educação permanente.

Espera-se com isso facilitar a comunicação entre ex-alunos e a Universidade, possibilitando a troca de informações profissionais, para que seja possível o melhoramento do curso, além da oferta pela universidade de cursos de pós-graduação e aperfeiçoamento que visem atualizar e atender às demandas sociais da Odontologia.

\section{METODOLOGIA}

A presente pesquisa configura-se como um estudo observacional descritivo, por meio de um método quantitativo.

Os sujeitos deste estudo foram egressos do curso de Odontologia da UFRN que concluíram a graduação nos anos de 2001 a 2011. Não foram incluídos aqueles que cursaram menos de cinco semestres na instituição.

Para o cálculo da amostra foi considerada uma população de 600 egressos da UFRN no período estudado, considerandose o ingresso semestral de 32 alunos e evasão aproximada de $5 \%$ por semestre.

$\mathrm{O}$ cálculo da amostra previu a participação de 84 egressos. Para o cálculo foi considerado $50 \%$ como percentual com o qual os fenômenos se verificariam na população, nível de confiança de $95 \%$ e margem de erro de $10 \%$. Considerando uma taxa de não resposta de 75\%, uma vez que os questionários seriam respondidos online, foram sorteados 147 sujeitos para a pesquisa. O questionário foi respondido por 92 sujeitos, entretanto, devido à incompatibilidade de respostas, cinco foram excluídos, de tal forma que a amostra final foi composta por 87 16 (1): 13-24, 2016. 
egressos.

Em função da inexistência de um questionário adequado que fosse referência para este estudo, foi realizada uma validação de conteúdo do instrumento da pesquisa para que fossem feitas adequações ao objeto que se pretendia medir. Esta validação foi realizada junto aos professores do curso de Odontologia da UFRN, os quais atribuíram escores em uma escala de Likert de cinco pontos, na qual foram avaliados: clareza das questões, aplicabilidade, necessidade de decisões subjetivas e vieses ${ }^{7}$.

A partir da validação foi realizado um estudo piloto com profissionais que possuíssem as mesmas características do estudo, mas que não compuseram a amostra final, o que permitiu maior adequação do questionário adotado.

O projeto de pesquisa foi aprovado pelo Comitê de Ética em Pesquisa da UFRN, por meio do parecer 399.179/2013.

Para desenvolvimento da pesquisa, foram identificados os e-mails dos egressos para encaminhamento do convite para participação, recebimento das orientações relativas à pesquisa, acesso e assinatura virtual do termo de consentimento livre e esclarecido, assim como ao link para a plataforma Google-Docs, na qual se encontrava depositado o questionário estruturado validado, permitindo sua autoadministração de forma online.

Foram encaminhados até três e-mails para cada participante da pesquisa. Aqueles que não responderam, foram contatados por meio das redes sociais, as quais se mostraram como excelente veículo para acesso aos sujeitos da pesquisa. Nesta fase da pesquisa participaram quatro alunos do $3^{\circ}$ período do curso de Odontologia da Universidade Federal do Rio Grande do Norte. O período de coleta de dados foi de janeiro a março de 2014.
A partir da aplicação do questionário foi construído banco de dados no software Excel composto pelas variáveis relativas ao tempo de ingresso no mercado de trabalho, participação em pós-graduação, ações desenvolvidas ao longo da graduação, inserção profissional atual e satisfação com a profissão. Os dados foram analisados por meio de estatística descritiva e inferencial, a partir do programa SPSS 20.0.

\section{RESULTADOS}

Dos 87 entrevistados, 47 (54\%) eram mulheres e 40 (46\%) eram homens. A quase totalidade (86) mantém algum vínculo empregatício na área de Odontologia, sendo que todos realizaram algum tipo de pósgraduação. Quanto à titulação, 68\% dos egressos são especialistas, $20 \%$ mestres e $12 \%$ doutores. A área de atuação com maior número de especialistas foi a Ortodontia (26,5\% do total), seguida pela Saúde Coletiva $(17,3 \%)$ e a Prótese Dentária $(12,7 \%)$.

Para $98 \%$ dos egressos, o tempo para ingresso no mercado de trabalho foi de até seis meses após a formatura, sendo que 59\% (51) ingressaram no mercado em até 1 mês.

Em relação às atividades complementares, a grande maioria dos profissionais (94\%) indicou que participou de pesquisa, monitoria ou extensão. Destes, 67 (82\%) afirmaram que esta participação contribuiu para sua inserção no mercado de trabalho.

Quanto ao setor em que os egressos estão inseridos no mundo profissional, 9\% estão vinculados apenas ao setor público, $59 \%$ apenas ao privado e $32 \%$ em ambos os setores.

Daqueles que apresentam vínculo exclusivamente com o setor público cinco trabalham em instituições de ensino (universidade ou instituto federal), um na Estratégia Saúde da Família e dois em outros postos de trabalho. A carga horária no setor corresponde, em sua maioria, de 20 a 40 horas 
semanais. O vínculo ficou equitativamente dividido entre contrato de trabalho (CLT) e estatutário. A remuneração mensal no setor público variou de $\mathrm{R} \$ 1.000,00$ a $\mathrm{R} \$ 5.4000$, sendo que $50 \%$ afirmaram ganhar entre $3.400,00$ e $5.400,00$ reais por mês. Com relação à satisfação com o setor público, $63 \%$ declararam como ótima ou boa, $12 \%$ como regular e $25 \%$ péssimo.

Dentro do setor privado, assim como no público, existem diversos postos de trabalho nos quais os profissionais estão inseridos (carteira assinada, prestação de serviços e participação nos lucros) sendo o autônomo o mais presente $(45,1 \%)$. A carga horária no setor corresponde, em sua maioria, de 30 a mais de 40 horas semanais (92\%). A remuneração mensal no setor privado variou de $\mathrm{R} \$ 1.000,00$ a mais de $\mathrm{R} \$ 5.4000$, sendo que $68 \%$ afirmaram ganhar mais de 5.400,00 reais por mês. Com relação à satisfação com o setor privado, $92 \%$ declararam ser ótimo ou bom, $4 \%$ regular e $4 \%$ ruim ou péssimo.

Vinte e sete egressos da amostra do estudo responderam que atuam tanto no serviço público quanto no serviço privado. Desses egressos, 70,4\% têm jornada de trabalho de 30 a 40 horas de trabalho semanais. Os demais $29,6 \%$ afirmaram trabalhar até 30 horas semanais. O tipo de vínculo para quem trabalha em ambos os setores ficou dividido entre contrato de trabalho (22,2\%), estatutário $(70,4 \%)$ e carteira assinada $(7,4 \%)$. A remuneração para quem divide seu expediente entre setor público e privado foi, principalmente, entre $\mathrm{R} \$ 2.000,00$ e $\mathrm{R} \$ 5.400,00$, com apenas 7,4\% que recebem mais de $\mathrm{R} \$ 5.400,00$. A maioria dos egressos respondeu também, estar satisfeito com as atividades realizadas, caracterizando sua inserção como boa ou ótima $(66,7 \%)$.

Os egressos de Odontologia afirmaram ter uma satisfação financeira média
(59\%) para o padrão de vida de um brasileiro, sendo que $40 \%$ sinalizaram haver uma boa perspectiva profissional na área. Não houve grande diferença quanto ao setor mais adequado ao perfil do profissional uma vez que $52 \%$ dos entrevistados alegaram terem mais afinidade com o setor privado e $48 \%$ com o setor público.

A estimativa de salário ideal, desejado pelos profissionais, variou entre $\mathrm{R} \$ 5.000,00$ e $\mathrm{R} \$ 15.000,00$, sendo a média de $\mathrm{R} \$ 9.300,00$ mensais. Além disso, os profissionais relataram, em sua maioria $(59,3 \%)$, que a carga horária adequada para desenvolver suas atividades seria de 30 a 40 horas semanais.

Quando comparada a variável sexo e às demais, foram obtidos os resultados expostos na tabela 1. A maioria das mulheres demorou mais de dois meses para começar a trabalhar após a formatura, enquanto para a maioria dos homens essa inserção se deu em até 1 mês da sua colação de grau; as mulheres que trabalham apenas no setor privado têm jornada de trabalho de até 40 horas semanais, ao mesmo tempo em que os homens trabalham mais de 40 horas semanais; a remuneração mensal no setor privado não variou quanto ao sexo. Quando os homens foram perguntados a respeito da atividade profissional que seria mais adequada em sua opinião para o desenvolvimento de suas atividades, a maioria relatou ser a privada a prática desejada, enquanto as mulheres relataram uma preferência pela prática na área pública.

O impacto do tempo de formado em relação ao ingresso no mercado de trabalho também foi avaliado (tabela 2). Os profissionais que tiveram sua formatura há mais tempo (8 a 13 anos), levaram mais tempo para ingressar no mundo do trabalho, já entre os que se formaram mais recentemente ( 3 a 7 anos), a maioria levou até um mês para estar empregada. Além disso, os profissionais que trabalham apenas no setor privado e estão 
formados de 3 a 7 anos têm remuneração mensal inferior a $\mathrm{R} \$ 3.400,00$ reais; já os que trabalham apenas no setor privado e estão formados de 8 a 13 anos têm remuneração mensal superior a $\mathrm{R} \$ 3.400,00$. Os profissionais formados mais recentemente (3 a 7 anos) consideram adequada a remuneração mensal de até $\mathrm{R} \$ 8.000,00$ para um cirurgiãodentista, enquanto os profissionais formados a mais tempo (8 a 13 anos) almejam uma remuneração adequada para Odontologia acima de $\mathrm{R} \$ 8.000,00$ mensais.

Tabela 1 - Associação entre sexo e tempo para ingresso no mercado de trabalho, remuneração mensal e carga horária no setor privado, inserção profissional adequada

\begin{tabular}{rrrrrrr}
\hline & \multicolumn{7}{c}{ SEXO } & & & \\
& \multicolumn{1}{c}{ Homens } & Mulheres & $\mathrm{X}^{2}$ & $\mathrm{P}$ \\
\hline Variável & $\mathrm{n}$ & $\%$ & $\mathrm{~N}$ & $\%$ & & \\
\hline Tempo ingresso mercado de trabalho & & & & & & \\
Até 1 mês & 29 & 72,5 & 22 & 47,8 & 5,397 & 0,020 \\
Mais de 2 meses & 11 & 27,5 & 24 & 52,2 & & \\
\hline $\begin{array}{c}\text { Até 3.401 reais } \\
\text { Remuneração mensal setor privado }\end{array}$ & 2 & 6,9 & 6 & 27,3 & 3,927 & 0,048 \\
Mais de 3.401 reais & 27 & 93,1 & 16 & 72,7 & & \\
\hline Carga horária no setor privado & & & & & & \\
Até 40 horas semanais & 12 & 41,4 & 15 & 68,2 & 3,607 & 0,058 \\
+ 40 horas semanais & 17 & 58,6 & 7 & 31,8 & & \\
\hline Inserção profissional adequada & & & & & & \\
Setor público & 9 & 22,5 & 32 & 69,6 & 18,999 & $<0,001$ \\
Setor privado & 31 & 77,5 & 14 & 30,4 & & \\
\hline
\end{tabular}

Tabela 2 - Associação do tempo de formado com tempo para ingressar no mercado de trabalho, remuneração média no setor privado e remuneração almejada

\begin{tabular}{rcccccc}
\hline & \multicolumn{7}{c}{ TEMPO DE FORMADO } & & \\
& \multicolumn{2}{c}{$3 \mathrm{a} 7$ anos } & 8 a 13 anos & $\mathrm{X}^{2}$ & $\mathrm{p}$ \\
\hline Variável & $\mathrm{n}$ & $\%$ & $\mathrm{n}$ & $\%$ & & \\
\hline Tempo para ingressar no mercado & & & & & & \\
Até 1 mês & 36 & 83,7 & 15 & 34,9 & 21,247 & $<0,001$ \\
Mais de 2 meses & 7 & 16,3 & 28 & 65,1 & & \\
\hline Até 3.401 reais & 8 & 29,6 & 0 & 0 & 8,434 & 0,004 \\
Mais de 3.401 reais & 19 & 70,4 & 24 & 100 & & \\
\hline Remuneração média setor privado & & & & & & \\
Até 8 mil reais mensais & 27 & 62,8 & 11 & 25,6 & 12,070 & 0,001 \\
+ 8 mil reais mensais & 16 & 32,2 & 32 & 74,4 & & \\
\hline
\end{tabular}


O tipo de pós-graduação foi dicotomizado em stricto sensu e lato sensu visando análise com variáveis relativas à remuneração e visão sobre adequação da inserção profissional (tabela 3). Quando relacionada à remuneração no setor público, os profissionais que realizaram pós-graduação stricto sensu recebem remuneração mensal maior que $\mathrm{R} \$$ 3.400,00. Já os profissionais que realizaram pós-graduação do tipo lato sensu possuem como remuneração mensal o valor de até $\mathrm{R} \$$ 3.400,00. Os egressos que realizaram pósgraduação do tipo stricto sensu afirmaram, em sua maioria, que a inserção mais adequada para o desenvolvimento de suas atividades profissionais deveria ser dentro do setor público, já os profissionais que realizaram pós-graduação do tipo lato sensu afirmaram ser o setor privado o mais adequado. O tipo de atividade adequada para os egressos que realizaram pós-graduação stricto sensu foi a docência/pesquisa, já os profissionais que realizaram pós-graduação lato sensu afirmaram, na grande maioria, ser o serviço a inserção adequada para realizar sua atividade laboral, de acordo com o seu perfil.

Tabela 3 - Relação entre tipo de Pós-graduação com remuneração, adequação da inserção profissional e tipo de atividade

\begin{tabular}{|c|c|c|c|c|c|c|}
\hline \multirow[b]{3}{*}{ Variável } & \multicolumn{4}{|c|}{ PÓS-GRADUAÇÃO } & \multirow{3}{*}{$\mathrm{X}^{2}$} & \multirow{3}{*}{$\mathrm{p}$} \\
\hline & \multicolumn{2}{|c|}{ Lato sensu } & \multicolumn{2}{|c|}{ Stricto sensu } & & \\
\hline & $\mathrm{n}$ & $\%$ & $\mathrm{n}$ & $\%$ & & \\
\hline \multicolumn{7}{|l|}{ Remuneração público/privado } \\
\hline Até 3.401 reais & 10 & 58,8 & 3 & 30,0 & 2,095 & 0,015 \\
\hline Mais de 3.401 reais & 7 & 41,2 & 7 & 70,0 & & \\
\hline \multicolumn{7}{|l|}{ Inserção profissional adequada } \\
\hline Setor público & 22 & 37,3 & 19 & 70,4 & 8,127 & 0,004 \\
\hline Setor privado & 37 & 62,7 & 8 & 29,6 & & \\
\hline \multicolumn{7}{|l|}{ Tipo de atividade adequada } \\
\hline Docência/pesquisa & 17 & 28,8 & 15 & 55,6 & 5,579 & 0,017 \\
\hline Serviço & 42 & 71,2 & 12 & 44,4 & & \\
\hline
\end{tabular}

\section{DISCUSSÃO}

Mulheres cirurgiãs-dentistas são a maioria em 25 dos 27 estados brasileiros, sendo o percentual de mulheres de $56,3 \%$ no país, bastante próximo dos achados no presente estudo (54\%). Na região Nordeste esse número passa de $60 \%{ }^{8}$. Essa expansão da mulher no mundo do trabalho é devida ao aumento da escolaridade, revertendo um quadro de desigualdade e consolidando uma nova diretriz em suas carreiras, deixando de ser apenas "do lar" e passando a dividir as despesas com os homens. No período de 1991 a 2004 o número de estudantes do sexo feminino no ensino superior cresceu $181 \%$, enquanto o crescimento de estudantes do sexo masculino foi de $148 \%$.

Todos os profissionais que compõem a amostra do estudo realizaram alguma pósgraduação, sendo que a maior parte do tipo lato sensu em sua área de atuação. Esse dado propõe, assim como em outro estudo ${ }^{10}$, que apesar dos estudantes concluintes de um curso de graduação em Odontologia considerarem uma provável inserção na Estratégia de Saúde da Família e terem uma percepção positiva 16 (1): 13-24, 2016. 
sobre ela, a grande maioria dos estudantes tem preferência pelas práticas clínicas tradicionais. Os autores defendem que esse fato ocorre, provavelmente, devido ao fato de grande parte dos currículos de Odontologia ser ocupado por disciplinas da área clínica, como acontece com o currículo do curso de Odontologia da UFRN. Assim, é provável que a maioria das pós-graduações, nas quais os egressos têm formação, tenham gênese na própria graduação, uma vez que indiretamente são levados a reproduzirem este tipo de prática, devido à conformação dos currículos da graduação em Odontologia.

Os números do Conselho Federal de Odontologia $(2008)^{8}$ mostram que a especialidade com o maior número de registros de cirurgiões-dentistas é a Ortodontia com 11.778 especialistas, o que corrobora com os dados obtidos no atual estudo. Entretanto, ao contrário do que configurou nosso estudo, a especialidade que possui menor número de registros, dentre as dez mais frequentes, foi a Saúde Coletiva, com 1430 profissionais registrados. Este dado pode ser subestimado, já que o não registro nessa área, não implica em limitações da prática profissional ${ }^{8}$, assim como a maioria daqueles que cursam este tipo de especialização não se inscrevem no CRO como tal.

Em relação ao ingresso no mercado de trabalho, outro estudo ${ }^{11}$ sinaliza resultados equivalentes aos nossos. Nele, 51,2\% dos sujeitos conseguiram ingressar no mercado de trabalho em menos de 1 mês após a colação de grau e $41,5 \%$ ingressaram em exatamente 1 mês após a formatura. Os autores atribuem a este fato existirem novos postos de trabalho na Odontologia que permitem esse ingresso precoce $^{11}$. Pesquisa apontava para uma saturação de mercado para a Odontologia, entretanto para a prática exclusivamente privada com vínculo trabalhista único de autônomo $^{12}$. A prática atual da Odontologia aponta para o assalariamento e para remuneração proveniente dos credenciamentos junto a planos de saúde e convênios, configurando um assalariamento indireto ${ }^{1}$, além da prática dentro do setor público, a partir da Política Nacional de Saúde Bucal ${ }^{13}$. Os resultados da presente pesquisa sugerem esse mesmo fato, a maioria dos profissionais formados entre 2001 e 2011 está inserida no setor privado, atuando principalmente em seus consultórios, como autônomos, provavelmente conveniados a tais credenciamentos.

Os resultados também demostram que uma parcela significante da amostra do estudo divide sua carga horária entre os setores público e privado, provavelmente como forma de complementar suas rendas e de estabelecerem um vínculo estável de trabalho, já que desses profissionais, a maioria tem como vínculo trabalhista o de estatutário. As atividades complementares constituem a extensão, a pesquisa e o ensino, na forma de monitorias. Os estudantes em contato com tais atividades abrem-se para um mundo de diversidades que os aproxima das realidades e vivências de que eles terão fora da universidade, configurando-se como uma experimentação da sua futura carreira, seja ela como docentes (monitorias e pesquisas) ou clínicos e/ou gestores (atividades de extensão). Sendo assim estas atividades além de nortearem os egressos quanto a que carreira seguir, são importantes meios de qualificação do profissional $^{14}$. A presente pesquisa demonstrou, por meio da resposta dos egressos de Odontologia, que todos tiveram inserção durante a graduação pelo menos em uma atividade complementar, e que isso para a maioria deles foi importante para que optassem por qual carreira seguir após sua formação. O atual regulamento dos cursos de graduação da Universidade Federal do Rio Grande do Norte ${ }^{15}$ prevê que pelo menos $5 \%$ da carga horária total dos cursos seja dedicada Revista da ABENO • 16 (1): 13-24, 2016. 
a atividades complementares, o que pode ser legitimado pelos resultados da presente pesquisa.

As inserções divididas entre os setores, sendo a maioria, ainda, no setor privado, mostra que a Odontologia passa por uma transição. Em um período recente, ela era uma das profissões mais elitizadas do país e a inserção pública era voltada apenas para o atendimento de escolares ${ }^{16}$. Este cenário não mudou muito na realidade de Natal, uma vez que segundo nossos resultados ainda há predominância dos profissionais no setor privado. Entretanto, nota-se uma transição entre os profissionais que atuam apenas nesse setor, dividindo-se agora entre ele e o setor público. Esse cenário é afirmado quando comparado a outras pesquisas que demostram o perfil do cirurgião-dentista brasileiro, bem como sua inserção. Estudos apontam uma atuação predominantemente autônoma ${ }^{8,17}$ assim como na nossa pesquisa.

A Odontologia está cada vez mais vinculada ao assalariamento, no qual a carga horária ultrapassa 40 horas semanais, tendo mais de um vínculo e remuneração reduzida atrelada aos convê-nios ${ }^{16}$, fato esse que se aproxima dos nossos resultados, que apontam para um período de transição, onde a maioria privada vai dando, aos poucos, espaço ao serviço público. Da mesma forma, outro estudo sinaliza que os profissionais apresentavam tendência ao trabalho assalariado, inseridas no setor público, principalmente ${ }^{18}$.

Corroborando com nossa pesquisa, $41,4 \%$ dos profissionais formados em Odontologia consideraram ser a inserção no mercado para o cirurgião-dentista brasileiro como boa, havendo melhor perspectiva nela do que em outros ramos profissionais ${ }^{11}$. No mesmo estudo em relação à satisfação com as atividades desenvolvidas como cirurgiãodentista, os entrevistados responderam que estavam satisfeitos, com um percentual de $82,9 \%$.

O valor da remuneração média almejada pelos egressos do curso de Odontologia, sujeitos da presente pesquisa, condiz com o que é pleiteado no Congresso Nacional mediante o projeto de Lei ${ }^{\circ} 3.734$, de $2008^{19}$, que visa assegurar por meio constitucional o salário mínimo de R\$ 7.000,00 mensais para cirurgiões-dentistas e médicos.

$\mathrm{O}$ ingresso precoce dos homens no mundo do trabalho se dá pela pressão social quanto ao provimento econômico familiar da figura masculina. Os homens têm a necessidade cultural e biológica de levar segurança a um lar, o que precipita a necessidade de ter um retorno financeiro rápido após a colação de grau ${ }^{9}$. Isso também explica a maior inserção dos homens no serviço privado, bem como sua preferência por ele, já que o serviço privado oferece, atualmente, devido à grande popularização da assistência odontológica por meio de clínicas populares, convênios e planos de saúde, maior número de vagas sem que haja a necessidade da conclusão de alguma pós-graduação ${ }^{1,13}$, além de não exigir, na maioria das vezes, um processo seletivo. A jornada de trabalho semanal também exemplifica diferenças biológicas e culturais entre os sexos. Conforme observado no presente estudo, a maioria das mulheres trabalha até 40 horas semanais. Isso se dá pelo papel doméstico da mulher ser independente da sua vida profissional, uma vez que as mulheres trabalham também em casa, o que exige uma carga horária adicional e inviabiliza uma efetivação de maior carga horária de trabalho ${ }^{9}$.

No presente estudo, os profissionais que estão formados entre 8 a 13 anos vivenciaram um período de transição no qual ainda predominava uma Odontologia liberal, 
de mercado, onde os profissionais recémformados vislumbravam a prática autônoma em consultórios ${ }^{5}$. Isso pode explicar o maior tempo para a inserção no mercado do que aqueles formados de 3 a 7 anos, já que abrir um negócio exige mais tempo e dinheiro, devido a características burocráticas da prática empresarial.

Os profissionais formados há mais tempo, segundo nosso estudo, já possuem renda próxima a $\mathrm{R} \$ 8.000,00$ mensais. Os resultados mostraram que eles recebem mais de 3.400 reais por mês, o que demonstra sua expectativa por uma renda superior a essa. Entretanto, os profissionais formados há menos tempo almejam uma renda mensal de até $\mathrm{R} \$ 8.000,00$, o que sugere que possuem inserções trabalhistas que os desvalorizam, certamente trabalham por meio de convênios e credenciamentos, que são conhecidos pela baixa remuneração ou mesmo no serviço público, que também segundo o presente estudo, apresenta remuneração inferior ao setor privado.

A remuneração maior para os indivíduos que realizaram pós-graduação stricto sensu sugere que a inserção desses profissionais é na Universidade, onde eles ingressam por meio de concurso público, provavelmente para compor o quadro de professores da instituição. Em contrapartida, os indivíduos que fizeram pós-graduação do tipo lato sensu, estão, em sua maioria, inseridos no serviço privado e recebem remuneração inferior, o que pode ser explicado pela prática atual privada ser caracterizada pela hegemonia dos credenciamentos e planos de saúde que pagam percentuais mínimos sobre a produção do cirurgião-dentista.

Existe diferença de propósito entre os tipos de pós-graduação, a stricto sensu, está mais voltada para a carreira acadêmica, forma o profissional para a docência e para a pesquisa dentro de sua área de atuação, são os mestrados e doutorados, já a lato sensu, forma o indivíduo especialista profissionalmente na sua área de escolha, não voltado para pesquisa ou docência, mas sim para a prática individual. Sabendo-se disso, infere-se com a pesquisa que os profissionais conseguem diferenciar bem estas duas práticas, uma vez que os que realizaram especialização afirmaram ser a prática clínica, no serviço, a mais adequada, e os profissionais que realizaram pós-graduação stricto sensu afirmaram ser a docência/pesquisa a atividade mais adequada segundo seu perfil profissional. Os resultados demostraram ser o serviço privado, ainda, o grande empregador para a Odontologia, fato esse que caracteriza o perfil do profissional, sendo ele formado para seguir uma especialidade e com um vislumbre de uma remuneração superior ao que recebe. Com isso, vê-se a partir dos resultados uma mudança gradual, e uma substituição do caráter privado da profissão, com egressos que atuam no setor público e com egressos que dividem sua carga horária entre os setores público e privado.

O fato de ainda haver a perpetuação da prática predominantemente privada mostra que as Diretrizes Curriculares Nacionais para os cursos de graduação em Odontologia ainda não estão bem compreendidas pelos diversos atores que participam da formação do profissional cirurgião-dentista ${ }^{20}$. Além disso, a inserção de dentistas na estratégia de saúde da família ainda não surte o efeito significativo esperado na mudança da formação em Odontologia ${ }^{21}$.

Com o passar do tempo a Odontologia deixa de ser caracterizada como uma prática eminentemente liberal à medida que vai se identificando uma demanda de assalariamento da profissão ${ }^{22}$. Isso ocorre em meio à transição de políticas de saúde, bem como da universalização da saúde. A prática privada 16 (1): 13-24, 2016. 
pura, em consultórios de maneira autônoma, dá espaço aos credenciamentos com convênios e planos de saúde. Junto, a isso há a consolidação da Política Nacional de Saúde Bucal com a inserção da equipe de saúde bucal na estratégia de saúde da família. Esse fato gera uma crise dentro do que seria o mercado ideal para o profissional cirurgiãodentista, acostumado com sua posição consolidada na prática privada, exclusivamente voltada para elites ${ }^{23}$.

Assim, vive-se em meio a uma mudança de paradigma dentro da Odontologia, e os resultados da pesquisa concordam com afirmação. A necessidade de universalização faz a transição da prática eminentemente privada, liberal, defasada e que não atende as demandas sociais, para a prática no serviço público, de acesso universal.

Entretanto ainda há uma precarização do emprego no serviço público, com baixos salários e com enfoque curativo da prática profissional. Por isso, apesar dessa necessidade de universalização, isso ainda não é uma realidade. Existe, pois, um amplo caminho para que seja alcançada e para que o setor público ganhe força de trabalho e valorize seus profissionais. Nesse início de século, grande parte dos serviços públicos brasileiros reproduz, mecânica e acriticamente, os elementos do modelo da prática odontológica no setor privado de prestação de serviços, sem se preocupar com a coletividade ${ }^{24}$.

Para que ocorra a universalização da atenção a saúde bucal de fato, faz-se necessário que o modelo liberal, assistencial, centrado na doença e com demanda fechada, evolua para um modelo de atenção integral à saúde, com enfoque preventivo que envolva ações de promoção e educação, para que haja melhoria da qualidade de vida da população e, com isso, o profissional formado em
Odontologia alcance seu espaço valorizado perante a sociedade e demais profissionais de saúde.

\section{CONCLUSÃO}

O serviço privado é, ainda, um grande empregador, fato que caracteriza o perfil do profissional e corrobora a grande predominância de disciplinas clínicas no currículo. A participação do aluno em atividades complementares configura-se estratégia essencial para a perspectiva da futura inserção profissional, assim como flexibilização curricular.

\section{ABSTRACT \\ Graduates of Dentistry: the dream of liberal profession faced with the reality of oral health}

Changes in the labor Dentistry demonstrate a transformation in the market, in practice and in the formation of dentists. A new professional is necessary to meet the health needs of society, with focus on attention to oral health with the epidemiological reality. The aim of this study was to evaluate the insertion of the graduates of Dentistry in Natal -RN in the labor market and its relationship with the curriculum and continuing education activities. The survey was developed through self-administered questionnaire composed of variables related to the time of entry into the labor market, participation in postgraduate actions developed over graduation, employability and job satisfaction. Results demonstrated that the private service is also a major employer, fact that determines the professional profile and supports the great predominance of clinical disciplines in the curriculum. The student's participation in complementary activities sets up essential strategies for future job prospects, as well as curricular flexibility. Despite the transition foreseen in the prospects of universal public access to oral health transition, great efforts are needed in continuing education for dentistry to reach its valued space in society and effectively fulfill their role as health care 
profession.

Descriptors: Professional Role. Staff Development. Dentistry. Job Market. Dental Staff.

\section{REFERÊNCIAS}

1. Moysés SJ. Política de saúde e formação de recursos Humanos em Odontologia. Rev ABENO. 2004; 4(1):7-30.

2. Brasil. VII Conferência Nacional de Saúde. Brasília, 1980.

3. Noro LRA, Ringeisen ATS. Saúde bucal e direito do consumidor. Pró-odonto. Prevenção. 2013;1(7):127-168.

4. Botazzo C. Sobre a bucalidade: notas para a pesquisa e contribuição ao debate. Ciênc Saúde Coletiva. 2006;11(1):7-17.

5. Manfredini MA, Moysés SJ, Noro LRA, Narvai PC. Assistência Odontológica Pública e suplementar no município de São Paulo na primeira década do século XXI. Saúde Soc São Paulo. 2012;21 (2):323-335.

6. Morita MC, Kriger L, Carvalho ACP, Haddad AE. Implantações das Diretrizes Curriculares Nacionais em Odontologia. Marigá: Dental Press International, 2007.

7. Barreira RB. Elaboração e validação de questionário para coleta de dados sobre serviços especializados de pacientes com imunodeficiências primárias. Dissertação (Mestrado). Pós-graduação em saúde da criança e da mulher. Instituto Fernandes Figueira - Fundação Osvaldo Cruz. Rio de Janeiro, 2007.

8. Morita MC, Haddad AE, Araújo ME. Perfil Atual e Tendências do Cirurgião Dentista Brasileiro. Maringá: Dental Press International, 2010.

9. Costa SM, Durães SJA, Abreu MHNG. Feminização do curso de Odontologia da Universidade Estadual de Montes Claros. Ciênc Saúde Coletiva. 2010,15(1):18651873.

10. Noro LRA, Torquato SM. Percepção sobre o aprendizado de saúde coletiva e o SUS entre alunos concludentes de curso de odontologia. Trab Educ Saúde. 2011;8(3):439-447.
11. Pinheiro VCM, Menezes LMB, Aguiar ASW, Moura WVB, Almeida MEL, Pinheiro FMC. Inserção dos egressos do Curso de Odontologia no mercado de trabalho. RGO. 2011;59(2):277-283.

12. Paranhos $1 r$. O mercado profissional na área de Odontologia - uma pequena reflexão. Odonto. 2011;19(38):5-6.

13. Freitas CHSM. Dilemas no exercício profissional da odontologia: autonomia em questão. Interface Comunic Saúde Educ. 2007;11(21):25-38.

14. Moura LFAD, Piauilino RJB, Araújo IF, Moura MS, Lima CCB, Evangelista LM, Lima MDM. Impacto de um projeto de extensão universitária na formação profissional de egressos de uma universidade pública. Rev Odontol UNESP. 2012;41(6):348-352.

15. Universidade Federal do Rio Grande do Norte. Resolução No 171/2013CONSEPE, de 5 de novembro de 2013. Aprova o Regulamento dos Cursos Regulares de Graduação da Universidade Federal do Rio Grande do Norte. Natal, 2013.

16. Saliba NA, Moimaz SAS, Prado RL, Garbin CAS. Percepção do cirurgiãodentista sobre a formação profissional e dificuldades de inserção no mercado de trabalho. Rev Odontol UNESP. 2012; 41(5):297-305.

17. Martelli PJL, Macedo CLSV, Medeiros KR, Silva SF, Cabral APS, Pimentel FC, Monteiro IS. Perfil do cirurgião-dentista inserido na Estratégia de Saúde da Família em municípios do estado de Pernambuco, Brasil. Ciênc Saúde Coletiva. 2010;15(suppl.2):3243-3248.

18. Nunes MF, Leles CR, Gonçalves MM. Gênero e escolha por especialidades odontológicas: estudo com egressos de uma universidade pública. Rev Odontol Bras Central. 2010;19(49):142-145.

19. Brasil. Projeto de Lei n.3734, de 15 de dezembro de 2008. Altera o salário mínimo dos médicos e cirurgiõesdentistas. Diário Oficial da República Federativa do Brasil, Poder Executivo.

20. Morita MC, Kriger L. Mudanças nos 
cursos de Odontologia e a interação com o SUS. Rev ABENO. 2004;4(1):17-21.

21. Freitas SFT, Calvo MCM, Lacerda JT. Saúde Coletiva e novas Diretrizes Curriculares em Odontologia: uma proposta para a graduação. Trab Educ Saúde. 2012;10(2):223-234.

22. Matos IB. Expectativas do exercício profissional de graduandos em odontologia. Tese (Doutorado em Ciências - Saúde Pública), Escola Nacional de Saúde Pública Arouca, FIOCRUZ, 2005.
23. Freitas CHSM. Dilemas do Exercício Profissional no Trabalho Liberal da Odontologia: a autonomia em questão. Tese (Doutorado). Programa de Saúde Coletiva. Instituto de Medicina Social. Universidade Estadual do Rio de Janeiro. Rio de Janeiro, 2004.

24. Narvai PC. Saúde bucal coletiva: caminhos da odontologia sanitária à bucalidade. Rev. Saúde Pública 2006:40(n. esp.):141-147.

Correspondência para:

Prof. Dr. Luiz Roberto Augusto Noro

e-mail: luiz_noro@hotmail.com

Departamento de Odontologia da UFRN

Avenida Salgado Filho, 1787

59056-000 - Natal/RN 